\title{
Commentary to the paper double neural tube defect: a case report and discussions on neural tube development by V. Ravindran
}

\author{
Dachling Pang
}

Received: 25 January 2010 / Accepted: 26 January 2010 /Published online: 12 March 2010

(C) The Author(s). 2010 This article is published with open access at Springerlink.com

This is a case report of a child with double neural tube defect (NTD) comprising a parietal encephalocoele and an open thoracic myelomeningocoele. The authors use this case to endorse the multi-site neural tube closure theory as aetiology for all multiple NTDs. Proponents of this theory claim that neural tube defects occur at "collision sites" of neural tube closure with opposing closure directions, and because up to five or six of these waves are thought to be operational, there are, accordingly, multiple collision sites. The multi-site closure theory was used originally to explain the different favoured locations of encephalcoeles, and as such, the theory is seductive. At collision sites, the overlying myocutaneous tissues may be potentially weaker and, therefore, susceptible to being stretched but not disrupted by a focal herniation of the alar plates of the already closed cranial neural tube and surrounding meninges. The disorganised gyral development and cortical dysplasia of the herniated brain may be secondary to early tissue distortion. The overlying skin and meninges are intact.

Spinal open neural tube defects (ONTD) are due to focal absence of neural plate closure, as shown in numerous, very credible animal experiments. The skin, muscles, neural arches and dura are wide open, and the exposed neural material is an unfused neural plate. This true "closure lesion" is thus fundamentally different from a "collision lesion" exemplified by the encephalocoele.

Most spinal ONTDs are terminal lesions involving the end of the primary neural tube, but there are rare examples of

\section{Pang}

Paediatric Neurosurgery, University of California,

Davis, CA, USA

\section{Pang $(\bowtie)$}

Regional Centre for Paediatric Neurosurgery,

Kaiser Permanente Hospitals,

Oakland, CA, USA

e-mail: pangtv@aol.com segmental lesions in which the "suspended" open neural placode is flanked by normal spinal cord both rostrally and caudally. The incomplete neural plate closure occurs in a square-pulse fashion followed by resumption of normal closure. Three percent of ONTDs in our unit are segmental placodes. Most hemi-myelomeningocoeles associated with split cord malformation (SCM) are segmental lesions. Limited dorsal myeloschisis (LDM), though not technically "open", is a segmental neural tube closure abnormality, as is dorsal lipoma, a lesion of segmental premature disjunction.

If there can be one segmental closure failure, why not two or even three square pulse insults, separated in time, causing in tandem closure lesions resulting in either two segmental ONTDs or one segmental and one terminal ONTD? Other multiple neural tube closure abnormalities, though rare, have been reported, such as double LDMs, double dorsal lipomas and double dermal sinus tracts. Even double SCMs caused by multi-focal gastrulation defects with multiple endomeschymal tracts are well known in the literature. Thus, multiple spinal ONTDs can conceivably occur without invoking the multiple closure-wave theory, which, in the spinal cord will produce a very different lesion.

It is not known why there should be abrupt recovery of normal neural tube closure after the square pulse insult. There could conceivably be transient presence of a teratogenic impulse that disturbs certain downstream transcription factors, without a fixed genomic mutation that would perpetuate the developmental error. It is thus the timing of the next transient insult that determines the location of the second neural tube defect, rather than the activities of the colliding zippers.

Open Access This article is distributed under the terms of the Creative Commons Attribution Noncommercial License which permits any noncommercial use, distribution, and reproduction in any medium, provided the original author(s) and source are credited. 